\title{
OPTIMAL LOCATION OF ELECTRONIC CHARITY BOXES IN CHARITY NGOS BY PROPOSING A COMBINED MATHEMATICAL MODEL
}

\author{
Meisam Omrani ${ }^{1}$, Zahra Naji-Azimi $^{1, *}$, Alireza Pooya $^{1}$ And Majid Salari ${ }^{2}$
}

\begin{abstract}
The topic of collecting public donations has always attracted the attention of charity Non-Governmental Organizations as their basic policy; nevertheless, despite its importance, not much scientific research has been conducted on the issue. The optimal location of electronic charity boxes is effective in optimizing the obtained benefits. In this paper, for the first time in the literature, a location problem is defined with the aim of maximizing people's motivation for money donation. We propose a new model to find the optimal location of e-charity boxes across the city with an aim to maximize the total amount of received benefits, as well as the total amount of donation motivation. To reach this aim, the effective criteria on the amount of gathered donation in each district and in each location type are investigated separately. Then, considering some constraints of the problem, a new mathematical model is proposed in order to determine the optimal location of e-charity boxes. We solve the model using LP-Metric, SAW, and TOPSIS methods, as a combination of Multi-Objective and Multi-Attributes Decision Making methods. Besides, we run the model in a real case study and 80 final locations are specified as the optimal locations in the studied city.
\end{abstract}

Mathematics Subject Classification. 97M40, 90B80, 90C10.

Received April 22, 2020. Accepted April 27, 2021.

\section{INTRODUCTION}

Sustainable development is a model of economic, social, and structural change which optimizes the current economic and social benefits without compromising the potential benefits of the future. From a social perspective, development will sustain if it creates homogeneous and interconnected communities in which socio-economic gaps are rare and the residents feel justice and equality. Sociologists propose two main concepts for social sustainability, i.e. the equal distribution of resources and services, and the commitment of members of the society towards each other [7]. Protecting the underprivileged individuals and families is one of the social responsibilities of members of a society, which should be carefully pursued in order to fight the harmful effects of poverty and to establish social justice throughout the societies. Alongside the personal duties of individuals, the performance of institutions, e.g. charity Non-Governmental Organizations, in organizing some of these tasks

Keywords. Location problem, multiple-objective decision making, multiple-attribute decision making, electronic charity boxes, charity Non-Governmental Organizations.

1 Department of Management, Faculty of Economics and Business Administration, Ferdowsi University of Mashhad, Mashhad, Iran.

2 Department of Industrial Engineering, Faculty of Engineering, Ferdowsi University of Mashhad, Mashhad, Iran.

*Corresponding author: znajiazimi@um.ac.ir, zahranaji@yahoo.com 
seems necessary. As a result, the increase in public donation can lead to development of the revenue sources for these organizations, thus leading to fulfilment of equity across the society. One of the novel efforts in this area is application of electronic charity boxes, through which the application of paper money will be eliminated and a step will be taken towards achievement of a cleaner environment. The traditional view of society, which regards the charity boxes as a symbol for donors and donation, has helped these boxes to remain as one of the main methods of fundraising despite their inefficiency. The inefficiency of these conventional boxes may be due to their maintenance costs, harmful impact of plastic boxes or paper money on the environment and people's health, their lack of security, and their negative impact on beautification of urban passages. Accordingly, electronic charity boxes, once designed and positioned properly, can help to reduce these disadvantages. Appropriate location of these e-boxes across the city, due to the high cost of their production, can bring about a significant competitive advantage for this instrument of earning public donations. However, there still remain a number of important questions: Where should the e-charity boxes be located? Which criteria are effective in locating them? Is it possible to implement a mathematical model to determine their appropriate locations due to the lack of relevant research in the field of public-donation collection facilities location, and in order to propose a mathematical model for e-charity boxes location, the present study aimed to investigate the objectives and the constraints of optimizing the location of these boxes. To define the objectives, some criteria, other than the amount of people's donation in the past, have been taken into consideration, e.g. the effective indices of charity attraction in different locations and districts. Therefore, the two objectives of maximizing the total amount of received benefit and the total amount of donation motivation were considered. This is for the first time in the literature for a location problem to be defined with the aim to maximize the public motivation for money donation. Also, some constraints like the number of available electronic boxes across the city and across each district or location should be included. Based on these objectives and constraints, we proposed a new mathematical model to increase the money donations. We applied both MODM and MADM methods for solving the model and applied it in a real case as well.

\section{LiteratURE REVIEW}

The three following issues were reviewed below, namely the location problem, the location of social services, and the influential criteria.

\subsection{Location problem}

Although no research was found in the literature to have simultaneously examined the problem of location and public donations, considering the similarity of the subject of collecting the public donations location with Maximal Covering Location Problem (MCLP) and billboards location, the most recent research on these issues were presented in this paper. The topic of MCLP as one of the types of facility location methods was first introduced by Church and Revelle in 1974 [8]. Berman et al. [4] have explored the probabilistic gradual covering location problem in a communication network with separate stochastic demands. In their study, two coverage radii are assumed for each node; the coverage of each point in the distance between these two radii is determined by a function, and the demand for each node is fully covered if its distance from the facility is less than smaller radius. Davari et al. [10] propose a maximal covering location model with a fuzzy coverage radius in a large scale in a hypothetical example; to solve the model, they apply greedy search algorithm. Lashgarian and Bushehri [1] have used network count location problem (NCLP) for modeling the billboard advertising according to the number of visitors, the advertising costs per billboard, and the total cost allocated to billboard advertising. Moghaddas and Taghizadeh [24] have applied maximal covering and allocation model using queuing theory in their study; they propose a new solution which divides the problem into smaller scales, so as to solve it using the branch and bound algorithm and greedy randomized adaptive search procedure (GRASP) method. Pereira et al. [29] present a hybrid algorithm consisting of a meta-heuristic adaptive large neighborhood search (ALNS) method and an exact method for solving the maximal covering and allocation location problems; this algorithm is applicable to small and medium samples; for larger samples, they propose an innovative approach, i.e. the 
flexible adaptive large neighborhood search (FALNS). Blanquero et al. [6] propose an optimization model for the MCLP. Their model is a Mixed-Integer Nonlinear Programming (MINLP) model which is solved by the branch and bound algorithm; their research problem is the optimal positioning of intersection safety cameras in an urban traffic network, with the aims to maximize road control and reduce the number of traffic accidents. Lotfi et al. [21] have studied billboard location according to five key factors including attractiveness, installation cost, design cost, the number of visitors, billboard sales revenue, and other sub-parameters such as the number of products, the number of quality levels, the number of billboards, and the number of potential locations for billboards and advertising billboards; they also propose a model for billboard location. According to the probable travel range, Lee and Han [19], have optimized the location of electric vehicle-charging stations as an urgent need for future cars and future roads; they have developed a mixed integer nonlinear programming formulation and propose a Benders-and-Price algorithm via combining the Benders decomposition and column generation to solve the proposed formulation. Coco et al. [9] investigate the min-max regret maximal covering location problem, as a robust counterpart to MCLP, in which the benefit of each column is uncertain and is modeled as an interval data; the application of this model is in large-scale disaster relief initiatives; they propose a MILP formulation and an exact and two approximation algorithms.

\subsection{Location of social services}

Patel [28] describes an experience with the application of operations research techniques in planning social service centers for the Dharampur area in India. This work involves designing a road network using a minimal spanning tree algorithm, as well as developing a schedule for the construction of the service centers using dynamic programming. Rahman and Smith [31] review the application of location-allocation models in planning the health service development in developing countries. Narasimhan et al. [25] present a decision support system for efficient service location design of an agency that provide services including automobile registrations, issuance of driver licenses, recreational vehicle registration, and personal identification registrations; their proposed methodology and decision support system employ data envelopment analysis (DEA) and mixed-integer programming (MIP) models to incorporate a number of factors including branch office efficiencies, budget restrictions, capacity limitations for transactions processing, and demand requirements. Park and Sohn [26] propose a novel framework, based on taxi trajectory data, for efficient locating of the bicycle-sharing stations as a substitute for short automobile trips; their results represent the application of two different location-allocation models, i.e. the p-median model and the MCLP. Gupta et al. [13] propose a solution for allocating the Common Service Centers (CSCs) for villages in a country according to their E-governance plan; they utilize the Fuzzy C-Means (FCM) algorithm for clustering the village dataset and finding a cluster center for CSC allocation; they also use the Particle Swarm Optimization (PSO) algorithm for further optimiziation of the results obtained from the FCM algorithm based on population. Tali et al. [33] propose a method for gradual optimization of urban fire-station plan based on GIS location allocation model, to serve as a tool to determine where and how many facilities are needed for fulfilment of all requirements. Pouraliakbari et al. [30] present a probabilistic maximal covering location model based on queuing theory for determining the optimal location of facilities in congested healthcare systems with referral hierarchical structure. Banerjee et al. [2] hypothesize that the closer the proximity to attractions or restaurants, the higher the road usage is intensity. Also the bike station suitability scores are calculated with regard to proximity to transit, attractions, restaurants and existing bike stations. They develop a location-allocation model based on GIS to maximize the market share; although this methodology is useful in identifying the new facility locations in any metropolitan city where maximum exposure is necessary, it is based on GIS.

\subsection{Effective criteria}

Marx and Carter [23] examine the factors influencing charitable giving during the first full year of the Great Recession; these factors include race, gender, income, experience, location and city of residence, age, household size, home wealth, religious affiliation, educational level, home ownership, occupational status, marital status, 
and computer ownership. Lwin and Phau [22] investigate the characteristics of Australian charitable donors; they consider some factors to be effective in helping, including gender, age, marital status, household income, level of education, family size, the number of children in the family, generosity, financial security, religiousness, and good attitudes towards charities and charitable organizations. Yao [35] identifies the factors affecting charitable giving as income, age, marital status, gender, religion, the number of children, affiliation to political parties, and social status. In blood donation, as a popular form of donation, Bekkers and Veldhuizen [3] consider two types of factors to be effective, i.e. social factors and previous statistics: "social factors" consist of separation of religions, percentage of immigrants, value of the house, income, percentage of car owners, welfare percentage, percentage of high school and college graduates, employment percentage, donation collection location, and social norms, whereas the "previous statistics" refer to participation rate in election and the percentage of people who are members of a community. Bielefeld, et al [5] identify that the number of health, education, and social service nonprofits in a given area is positively influenced by block group income, age, minority percentage, and racial heterogeneity.

\section{ThEORETICAL FOUNDATIONS}

\subsection{Location problem models}

Location problem is one of the branches of operations research that reduces the costs and maximizes the success rates. Location problem issues are very diverse, with various classifications being proposed. Examples of classic location problems in the classification based on the modeling and problem-solving approach include Median Location Problem, Center Location Problem, Covering Location Problem, Warehouse Location Problem, Noxious or Obnoxious Location Problem, and Hub Location Problem [11]. In more details, it seems that a number of topics including Maximal Available Location, Maximal Visibility Location, and Billboard Location may have similarities with the topic of the present article; to be more exact, it can be noted that the Maximal Available Location consists of issues of maximizing the population coverage using an available facility, within a certain time standard and with the reliability of; also, the focus is on the facilities that are available at a time but are occupied by another person in another time. On the other hand, the models associated with Maximal Visibility Location assume that the facility has conditions that can provide a wide range of vision; therefore, these models are used in such situations as the location of security cameras, watchtowers, and fire towers. Besides, in Billboard Location based on the volume of traffic, the matter of attention is on the maximization of people who see the facility. Covering Location Problem aims to maximize the number of people who are going to be covered. Accordingly, more similarities to location of e-charity boxes can be found in Covering Location Problem and Billboard Location.

In the simple covering location model, the objective is to maximize covered customers with a predetermined number of facilities. According to equations (3.1)-(3.3) in the simple model, $I$ and $J$ are the set of demand points and the set of potential facility locations, respectively; $a_{i}$ is the people covered by the facility $i$, and $P$ is the total number of facilities; $N_{i}$ is the set of neighbour facilities that can cover demand point $i$, and $x_{j}$ and $y_{i}$ are the problem variables. If a facility is allocated to site $j$, then $x_{j}=1 a$ and otherwise $x_{j}=0$. Constraint (3.2) allow $y_{i}$ to equal 1 only when one or more facilities are established at sites in the set $N_{i}[8]$.

$$
\begin{aligned}
& \max Z=\sum_{i \in I} a_{i} y_{i} \\
& \text { s.t. } \\
& \sum_{j \in N_{i}} x_{j} \geq y_{i}, \\
& \sum_{j \in J} x_{j}=P,
\end{aligned}
$$




$$
x_{i} y_{i} \in\{0,1\} \quad \forall i \in I, \forall j \in J .
$$

In the simpler version of the Billboard Location problem, according to equations (3.5) and (3.6), the number of visitors is considered as $v_{a}, c_{a}$ stands for the advertising costs on billboard $a$, and $C$ is the total cost allocated to billboard advertising; $x_{a}$ is decision variables for network count location problem, where $x_{a}=1$ if link a is selected as an informative link, and 0 otherwise [1].

$$
\begin{aligned}
& \max Z=\sum_{a} v_{a} x_{a} \\
& \text { s.t. } \\
& \sum_{j \in N_{i}} c_{a} x_{a} \leq C \\
& x_{a} \in\{0,1\} .
\end{aligned}
$$

\subsection{Multiple Attribute Decision Making (MADM)}

Even when the existing criteria are complex, multiple attribute decision making is an excellent tool for evaluating, ranking, and prioritizing the options [12]. Most of these methods include steps in criteria determination, the option's rate determination in the criteria, normalization, determination of criteria's weights, and eventually option selection, despite the fact that they are different in how to reach weighing, normalization, and criteria aggregation [16]. There have been various classifications of MADM [15,17,36], one of which categorizes them into compensatory and non-compensatory tools. Whenever there is an interaction among the criteria through which the changes in one criteria are compensated by changes in another criteria, the model is called Compensatory; otherwise, it is known as non-compensatory [17]. Compensatory methods include such methods as Simple Additive Weighing (SAW), Order of Preference by Similarity to Ideal Solution (TOPSIS), and Analytical Hierarchy Process (AHP). The following sections elaborate on Simple Additive Weighing and TOPSIS methods, which are applied in the present study.

\subsubsection{Simple Additive Weighing (SAW) method}

The most widely-used method in multi-criteria decision making (MCDM) models is SAW [15]. In this method, the score of each option is obtained via aggregating the values of that option in different criteria, taking into account the weight of each criterion, so that the relative weights are directly provided by the decision maker [32]. It is the simplest multiple attribute decision making method in which the eventual rate of each option is estimated by additive weighing of all values of a parameter. It is comprised of three major phases:

(1) Linear normalization of data matrix in such a way that if the criterion has a positive value, we use equation (3.8) and if the criterion has a reverse value, equation (3.9) is used, where the merit of alternatives $A_{i}$, $i=1,2, \ldots, n$, is evaluated according to criteria $j, j=1,2, \ldots, m$, as $r=\left(r_{i j}\right)$ and the values of $n_{i j}$ are their normalized scores.

$$
\begin{aligned}
n_{i j} & =\frac{r_{i j}}{\max r_{i j}} \\
n_{i j} & =\frac{\min r_{i j}}{r_{i j}} .
\end{aligned}
$$

(2) Designation of Criteria' weights $\left(w_{j}\right)$ through the experts' opinion or quantitative methods such as Shannon entropy.

(3) According to equation (3.10), the final value of each alternative is calculated and the best alternative $\left(A^{*}\right)$ is chosen [34].

$$
A^{*}=\left\{A_{i} \mid \max \sum_{j=1}^{n} w_{j} n_{j}\right\} .
$$




\subsubsection{The Order of Preference by Similarity to Ideal Solution (TOPSIS)}

TOPSIS was first introduced by Hwang and Yoon, as one of the distance-based methods [15]. The main source of TOPSIS is the calculation of Euclidean distance of decision-making alternatives from positive ideal solution (PIS) and negative ideal solution (NIS) [15]. In TOPSIS model, the preferred alternative is the alternative which has the least distance from the positive ideal solution (PIS) as well as the highest distance from the negative ideal solution (NIS). The result of these two distances is expressed in the form of closeness coefficient. Accordingly, an alternative which has a higher closeness coefficient is known as the preferred alternative [18,20]. The TOPSIS method for rating the options can be described as follows [15]:

(1) Create an evaluation matrix consisting of $m$ alternatives and $n$ criteria, with the intersection of each alternative and criterion given as $r_{i j}$, therefore it is a matrix $\left(r_{i j}\right)_{m \times n}$.

(2) Normalization of data matrix using Euclidean class norm, by equation (3.11).

$$
n_{i j}=\frac{r_{i j}}{\left(\sum_{i=1}^{m} r_{i j}^{2}\right)^{\frac{1}{2}}} .
$$

(3) Designation of criteria' weights $\left(w_{j}\right)$ by means of experts' opinion or quantitative methods such as Shannon entropy, then obtaining the normalized weights matrix by equation (3.12).

$$
v=n_{i j} \times w_{j} .
$$

(4) Determination of an ideal solution for positive and negative criteria. In order to determine an ideal positive solution (vector $V_{j}^{+}$), the largest amounts are applied to the positive criteria and the smallest amounts to the negative ones. In doing so, for an ideal negative solution (vector $V_{j}^{-}$), the smallest amounts are applied to the positive criteria and the largest amounts to the negative ones.

(5) Calculation of every option's distance to the positive and negative ideals. Every option's Euclidean distance to the positive ideal $\left(d_{i}^{+}\right)$and to the negative ideal $\left(d_{i}^{-}\right)$is calculated using equations $(3.13)$ and $(3.14)$, respectively.

$$
\begin{aligned}
& d_{i}^{+}=\left(\sum_{j=1}^{2}\left(v_{i j}-v_{j}^{+}\right)^{2}\right)^{\frac{1}{2}} \\
& d_{i}^{-}=\left(\sum_{j=1}^{2}\left(v_{i j}-v_{j}^{-}\right)^{2}\right)^{\frac{1}{2}} .
\end{aligned}
$$

(6) Determination of relative closeness of an option to an ideal solution by equation (3.15):

$$
C_{i}=\frac{d_{i}^{-}}{d_{i}^{-}+d_{i}^{+}}
$$

(7) Determination of Option's rate based on $C_{i}$ amounts.

\subsection{Multiple Objective Decision Making (MODM)}

In most real problems, because of the contradiction among a model's objectives, a plausible answer that optimizes a target function cannot lead to the optimization of other objective functions; therefore, decision making for such situations requires an effective and preferred answer. The models to reachan effective solution for a multi-objective problem can be divided into four sets, including decision-making models in which the decision maker is known prior to, during, or after solving the problem, or the decision maker is notknown [14]. LP-Metric method seeks to minimize the sums of relative deviation of objectives from the optimized amounts. 


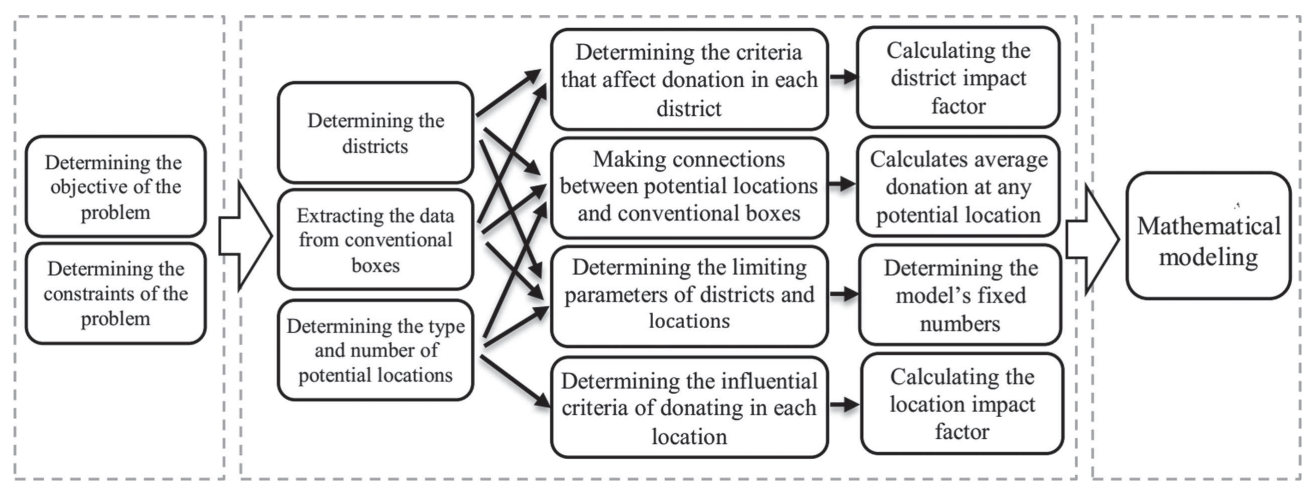

Figure 1. The process of reaching the mathematical model.

In order to prevent the effect of measuring scale, normalization is done by doing one division, whose objective function is defined according to equation (3.16), where $z_{i}^{*}$ stands for the optimized amount of the objective $i$ considering the constraints, $\gamma_{i}$ the weight of objective $i$, and $p$ the degree of emphasis on the existing deviations. Practically, in this way, the model changes from linear to nonlinear [27].

$$
\operatorname{Min} z=\left(\sum_{i=1}^{n} \gamma_{i}\left|\frac{z_{i}^{*}-z_{i}}{z_{i}^{*}}\right|^{p}\right)^{\frac{1}{p}} .
$$

\section{Modeling the PROBLEM}

The present study is based on Imam Khomeini Relief Committee's intention to install a number of e-charity boxes across Mashhad city, northeastern Iran. The Imam Khomeini Relief Committee can be considered as the largest organization across the country for collecting public donation, organizing and addressing the livelihoods of the poor and needy people. Although the institution's plan was to replace the conventional charity boxes with the electronic ones, it should be noted that the implementation of this plan may take several years. Moreover, because of some reasons including the exorbitant number of conventional charity boxes, and the need for high security and the infrastructure for installing new charity boxes, the Relief Committee is allowed to locate the e-boxes based on the locations rather than the pathways. The study's assumptions, the process of modeling, the variables, the parameters, the constraints, the objectives, and the mathematical model are fully elaborated in the following section. Figure 1 demonstrates the process of reducing the mathematical model.

\subsection{Problem assumptions}

(1) The profit obtained from each facility (i.e. charity box) is based on the average monthly money donation.

(2) District classification is based on the smallest division in the municipality. The term "neighborhood" indicates the divisions in municipality, yet the present study exerts the term "district".

(3) It extracts the potential districts based on the existing districts in the urban systems.

(4) The data related to charity boxes are based on the collected data of charity boxes in Imam Khomeini Relief Committee's systems.

(5) At each potential point, the motivation for money donation is different. Now, if we want to calculate the amount of motivation to donate at any potential point, the location type and district of that point should be considered. Accordingly, the amount of donation motivation in a facility includes both district $i$ 's impact factor $\left(\mathrm{DIF}_{i}\right)$ and location $j$ 's impact factor $\left(\mathrm{LIF}_{j}\right)$. 
TABLE 1. Problem parameters.

\begin{tabular}{lll}
\hline \hline Parameters & Symbol & Definition/related index \\
\hline Set of districts & $I$ & \\
Number of municipality districts & $m$ & $i \in I=\{1,2, \ldots, m\}$ \\
Set of types of locations & $J$ & $j \in J=\{1,2, \ldots, n\}$ \\
Number of types of locations & $n$ & \\
Set of locations of the type $j$ in the district $i$ & $K_{i j}$ & $k \in K_{i j}=\left\{1,2, \ldots, o_{i j}\right\}$ \\
Number of type $j$ locations in district $i$ & $o_{i j}$ & \\
Relative profit obtained from installing the facilities in location & $k$ & $b_{i j k}$ \\
which is type $j$ in district $i$ & \\
Impact factor of district $i$ based on the donation motivation & $\operatorname{DIF}_{i}$ \\
Impact factor of location type $j$ based on the donation motivation & $\operatorname{LIF}_{j}$ \\
Maximum charity boxes (e-charity boxes) & $P$ \\
Maximum installable facilities in district $i$ & $\operatorname{MFD}_{i}$ \\
Maximum installable facilities in location type $j$ & $\mathrm{MFL}_{j}$ \\
\hline
\end{tabular}

\subsection{Problem's objective functions}

(1) Maximizing the total amount of the obtained profit from the facilities.

(2) Maximizing the total amount of donation motivations based on the impact factors of districts and location types.

\subsection{Constraints of the problem}

(1) The total number of facilities cannot exceed the specified $P$ number.

(2) There should be at least one charity box (facility) in each district.

(3) There should be at least one charity box (facility) in each location type.

(4) Maximum installable facilities in district $i$ is the amount of $\mathrm{MFD}_{i}$.

(5) Maximum installable facilities in location type $j$ is the amount of $\mathrm{MFL}_{j}$.

\subsection{Model variables}

$$
x_{i j k}= \begin{cases}1, & \text { if the facility is installed in location } k \text { of type } j \text { in district } i \\ 0, & \text { otherwise }\end{cases}
$$

\subsection{Problem parameters}

Problem parameters are defined according to Table 1.

\subsection{Mathematical model}

Equations (4.1)-(4.8) indicate the mathematical model of the present problem

$$
\begin{aligned}
& Z_{1}=\operatorname{Max} \sum_{i \in I} \sum_{j \in J} \sum_{k \in K_{i j}} b_{i i j k} x_{i j k} \\
& Z_{2}=\operatorname{Max} \sum_{i \in I} \sum_{j \in J} \sum_{k \in K_{i j}}\left(\operatorname{DIF}_{i}+\operatorname{LIF}_{j}\right) x_{i j k}
\end{aligned}
$$

subject to:

$$
\sum_{i \in I} \sum_{j \in J} \sum_{k \in K_{i j}} x_{i j k} \leq P
$$




$$
\begin{array}{ll}
\sum_{j \in J} \sum_{k \in K_{i j}} x_{i j k} \geq 1, & \forall i \in I \\
\sum_{i \in I} \sum_{k \in K_{i j}} x_{i j k} \geq 1, & \forall j \in J \\
\sum_{j \in J} \sum_{k \in K_{i j}} x_{i j k} \leq \mathrm{MDF}_{i}, & \forall i \in I \\
\sum_{i \in I} \sum_{k \in K_{i j}} x_{i j k} \leq \mathrm{MFL}_{j}, & \forall j \in J \\
x_{i j k} \in\{0,1\}, & \forall i \in I, \forall j \in J, \forall k \in K_{i j} .
\end{array}
$$

Function number (4.1) indicates the primary objective of the problem which is maximizing the total amount of the obtained profit from the facilities. Furthermore, since the nature of the service provided by these charity boxes is merely centered on beneficence and its addressees do not seek it according to their needs, another objective is added to the model that aims the maximizing donation motivation based on the impact factors of districts and locations, which is shown in function (4.2). Constraint (4.3) is about the total number of charity boxes used for locating, which should not exceed the specified $\mathrm{P}$ number. The topic of e-charity boxes is so new that Imam Khomeini Relief Committee will certainly aim to work on its acculturation among people. That is why the researcher has defined some constraints to direct the model toward this objective. Constraints (4.4) and (4.5) make it possible for every district to retain at least one e-charity box. Constraints (4.6) and (4.7) seek to avoid charity box cluster in one district of various location types. Since the assumption is that there is potential chance for allocating or not allocating a location to charity boxes, the definition of variables in constraint (4.8) is binary.

Using the LP-Metric method explained in equation (3.16), the above multi-objective model can be altered into one-objective model as in equation (4.9).

$$
\operatorname{Min}\left[\frac{z_{1}^{*}-\sum_{i \in I} \sum_{j \in J} \sum_{k \in K_{i j} b_{i j k} x_{i j k}}}{z_{1}^{*}}+\frac{z_{2}^{*}-\sum_{i \in I} \sum_{j \in J} \sum_{k \in K_{i j}\left(\mathrm{DIF}_{i}+\mathrm{LIF}_{j}\right) x_{i j k}}}{z_{2}^{*}}\right] .
$$

Keeping the same set of constraints, the weights of all objectives were considered the same and $\mathrm{p}$ was equal to 1.

\section{Computational Results}

The mathematical model in Sections 4-6 was designed based on the data provided by Relief Committee and through the following steps so as to reach a plausible answer.

\section{Step 1. Collecting data regarding the locations}

According to geographical map, Relief Committee has several offices across the city of Mashhad. Considering the large size of this city, one office was chosen as a case to be studied. As it can be seen in Figure 2, the chosen office is privileged over other offices because it is the largest Imam Khomeini Relief Committee office in Mashhad and it's scope of activity is within the coty's boundaries; in other words its activity does not reach the outskirts of the city. Also, based on the existing information on Mashhad's municipality SDI system, 43 districts were identified in the area under study, as represented in Figure 3, Afterwards, according to Map system of Mashhad's municipality Information and Communications Technology office, 21 locations active in 8 types of activities were chosen out of the total number of 1024 locations, as shown in Table 2.

The distribution of each location type (parameter $o_{i j}$ ) is also demonstrated in Table 3. 


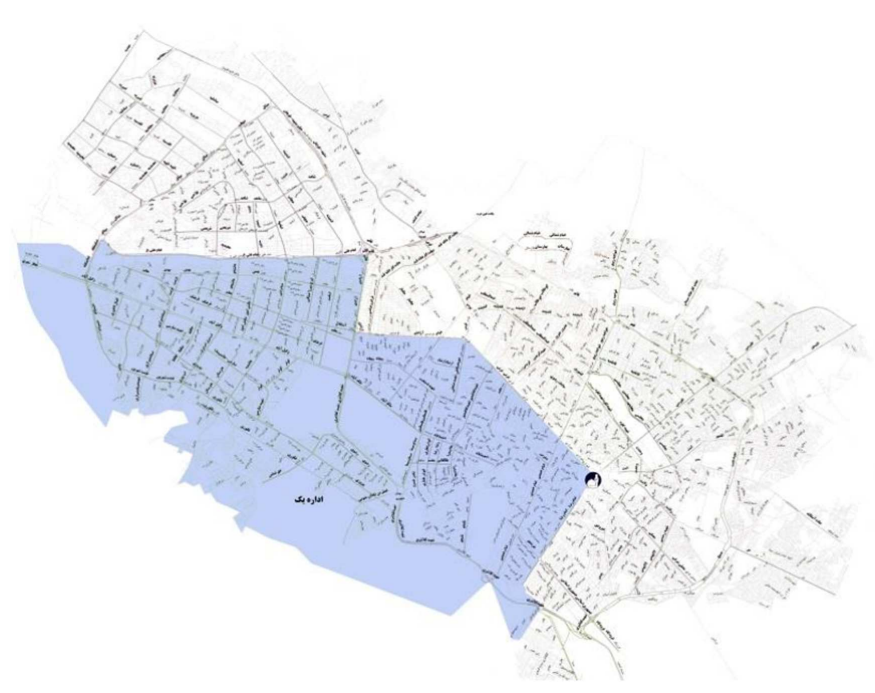

Figure 2. The limited area under the study in Mashhad.

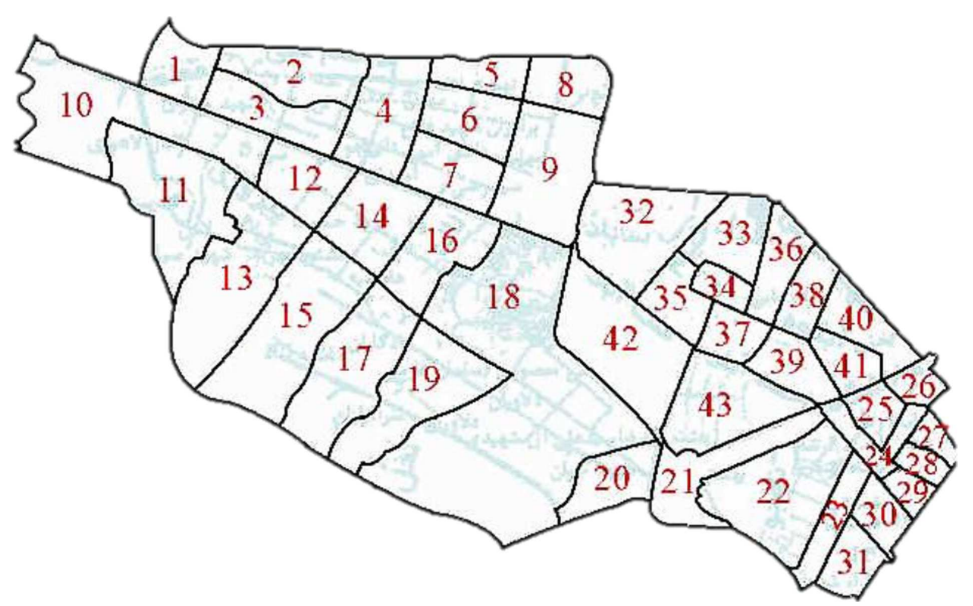

FiguRE 3. The limited area under the study in Mashhad.

\section{Step 2. Collecting data relating to public donation}

According to the last two years' information of about 25000 small, medium, and big conventional charity boxes in the Relief Committee's office under study, firstly the location of each box was specified on the 43 municipality districts. Next, the potential locations were related to one or more conventional charity boxes to calculate the mean donation in each potential location.

\section{Step 3. Determining what criteria in each district have impact on the donations (district impact factor, $\mathrm{DIF}_{i j}$ )}

Simple weighed sum method was applied as a multiple decision-making method to determine every district's impact factor. In other words, the ultimate output of simple weighed sum method was considered as the district's impact factor. Hence, the criteria of the model were identified in two groups: the first group was based on public donations in each district, whereas the second was based on using the relevant social factors of the district. 
TABLE 2. Number and type of potential locations.

\begin{tabular}{llll}
\hline \hline Type of the activity of the location & $j$ & The name of the location & Number \\
\hline Therapeutic and Sanitary & 1 & Hospitals & 18 \\
& 2 & Clinics & 34 \\
& 3 & Health Centers & 16 \\
\hline Educational & 4 & Schools of Seminaries & 17 \\
& 5 & Universities and Institutes of Higher Education & 101 \\
& 6 & High Schools & 93 \\
\hline Religious & 7 & Mosque and Hussainiya & 197 \\
\hline Transportation & 8 & Bus Terminals & 5 \\
& 9 & Subway Stations & 46 \\
& 13 & Gas Stations & 15 \\
& 14 & CNG Stations & 5 \\
\hline Official Services & 10 & Governmental Offices & 144 \\
\hline Shopping and Shopping Centers & 11 & Shopping Centers & 58 \\
& 12 & Supermarkets & 16 \\
\hline Artistry and Cultural Centers & 15 & Movie Theaters & 9 \\
\hline Residential Centers & 16 & Museums & 18 \\
& 17 & Libraries & 1 \\
& 18 & Pilgrims Residential & 62 \\
& 19 & Hotels & 76 \\
\hline & 20 & Motels & 89 \\
\hline
\end{tabular}

TABLE 3. Distribution of each type of location in different districts (parameter $o_{i j}$ ).

\begin{tabular}{|c|c|c|c|c|c|c|c|c|c|c|}
\hline $\begin{array}{l}\text { District/type } \\
\text { of location }\end{array}$ & Hospital & Clinic & $\begin{array}{l}\text { Health } \\
\text { Center }\end{array}$ & Seminary & $\begin{array}{l}\text { University } \\
\text { and } \\
\text { College }\end{array}$ & $\ldots$ & Hotel & Motel & Inn & Total \\
\hline 1 & & & & & & .. & Hotel & Motel & Inn & 4 \\
\hline 2 & & & 1 & & 3 & $\ldots$ & & & & 13 \\
\hline$\cdots$ & & & & & & $\begin{array}{l}\cdots \\
\ldots\end{array}$ & & & & 3 \\
\hline 43 & & & 3 & & 1 & $\ldots$ & 1 & 1 & 3 & 46 \\
\hline Sum & 18 & 34 & 16 & 17 & 101 & $\ldots$ & 62 & 76 & 89 & 1024 \\
\hline
\end{tabular}

Because the data from the first group were related to the data obtained in Step 2, three criteria were identified, which are presented in equations (5.1)-(5.3).

Mean of donations from the pathways $=\frac{\text { Sum of public donation from big boxes in the district }}{\text { The total number of big boxes in the district }}$

$$
\begin{aligned}
\text { Mean of donation from households } & =\frac{\text { Sum of donation from medium and small boxes of the district }}{\text { Total number of medium and small boxes of the district }} \\
\text { Mean of total donation } & =\frac{\text { Sum of public donation from all boxes }}{\text { District population }}
\end{aligned}
$$

As previously mentioned in the literature review, various factors such as income, age, number of people in a family, religious orientations, etc., were taken into consideration in order to obtain the second group criteria, which are effective social public donation factors of the districts. Due to the unavailability of some data, the 
TABLE 4. Weight of criteria that influence donation in each district.

\begin{tabular}{lllll}
\hline \hline Criteria & $\begin{array}{l}\text { Mean of pathway } \\
\text { donations in the district }\end{array}$ & $\begin{array}{l}\text { Mean of household } \\
\text { donations }\end{array}$ & $\begin{array}{l}\text { Mean of donations in } \\
\text { the population }\end{array}$ & $\begin{array}{l}\text { The proportion of the } \\
\text { total } \\
\text { households in } \\
\text { the pulation }\end{array}$ \\
\hline Weight & 0.1576 & 0.1304 & 0.2056 & 0.1032 \\
\hline Criteria & $\begin{array}{l}\text { The proportion of total } \\
\text { above-twenty-year-old } \\
\text { residents in the district } \\
\text { population }\end{array}$ & $\begin{array}{l}\text { The proportion of } \\
\text { employed people in } \\
\text { the district population }\end{array}$ & $\begin{array}{l}\text { The percentage of } \\
\text { house owners }\end{array}$ & $\begin{array}{l}\text { The percentage of } \\
\text { houses bigger than } \\
100 \text { square meters }\end{array}$ \\
\hline Weight & 0.0978 & 0.1413 & 0.0869 & 0.0760 \\
\hline
\end{tabular}

TABLE 5. The amount of district impact factor $\left(\mathrm{DIF}_{i}\right)$.

\begin{tabular}{llllllllll}
\hline \hline District & $\begin{array}{l}\text { Impact } \\
\text { factor }\end{array}$ & District & $\begin{array}{l}\text { Impact } \\
\text { factor }\end{array}$ & District & $\begin{array}{l}\text { Impact } \\
\text { factor }\end{array}$ & District & $\begin{array}{l}\text { Impact } \\
\text { factor }\end{array}$ & District & $\begin{array}{l}\text { Impact } \\
\text { factor }\end{array}$ \\
\hline 1 & 0.3649 & 10 & 0.4652 & 19 & 0.3417 & 28 & 0.6564 & 37 & 0.4549 \\
2 & 0.2991 & 11 & 0.3899 & 20 & 0.3554 & 29 & 0.5770 & 38 & 0.4185 \\
3 & 0.3748 & 12 & 0.4051 & 21 & 0.5220 & 0 & 0.4362 & 39 & 0.4896 \\
4 & 0.3889 & 13 & 0.3603 & 22 & 0.4160 & 31 & 0.4097 & 40 & 4046 \\
5 & 0.3615 & 14 & 0.4703 & 23 & 0.4344 & 32 & 0.4611 & 41 & 0.4576 \\
6 & 3911 & 15 & 0.3932 & 24 & 0.5353 & 33 & 0.4583 & 42 & 0.4787 \\
7 & 0.4303 & 16 & 0.4280 & 25 & 0.5504 & 34 & 0.36224 & 43 & 0.4864 \\
8 & 0.751 & 17 & 0.3386 & 26 & 0.5563 & 35 & 0.4651 & & \\
9 & 0.4003 & 18 & 0.3803 & 27 & 0.8869 & 36 & 0.4328 & & \\
\hline
\end{tabular}

present study utilized the information from the National Census Bureau to find the criteria. Although much of the information from the census bureau is demographic, it should be noted that: firstly there is precise and accessible information about the districts; secondly, there exist data that are indirectly relevant to the above criteria. Therefore, these criteria include the proportion of total households in the district population, the proportion of total above-twenty-year-old residents in the district population, the proportion of the employed people in the district population, the percentage of house owners, and the percentage of houses bigger than 100 square meters in the total number of houses in the district. Both qualitative approach (expert's view) and quantitative approach were applied with the aim to estimate the weights of the criteria. Five experts in the field of public donation helped to obtain the weights of the criteria in the present study. Table 4 indicates the weights of each of these criteria. Based on the 8 criteria, the weight of each criterion and the simple weighted sum method, the impact factor of each district was obtained, which is presented in Table 5.

\section{Step 4. Determining what criteria in each location have impact on the donations (location impact factor, $\mathrm{LIF}_{j}$ )}

Effective criteria of fund-raising in each location were identified by means of face-to-face interviews with four experts in public donation. The most noteworthy extracted criteria are presented in Table 6. Again as in Step 3 , the weight of each criteria was also obtained through surveys from five experts. Impact factor values of all 21 locations were obtained by a Likert scale questionnaire. Similar to the previous step, five experts in public donation filled out the questionnaires about both determining the weight of criteria and the value of criteria in locations. Considering the presence of both positive criteria (religious nature, probable presence of danger or threat, human traffic rate, the availability of donation for the donors, and probable women presence) and 
TABLE 6. Weight of effective donation factors in terms of location $\left(\operatorname{LIF}_{j}\right)$.

\begin{tabular}{llll}
\hline \hline Criteria & Religious nature & Recreational nature & $\begin{array}{l}\text { The probability of danger } \\
\text { in the location }\end{array}$ \\
\hline Weight & 0.1714 & 0.1333 & 0.2286 \\
\hline Criteria & Human traffic rate & $\begin{array}{l}\text { Donation availability for } \\
\text { the donators }\end{array}$ & $\begin{array}{l}\text { The probability of women } \\
\text { presence }\end{array}$ \\
\hline Weight & 0.2 & 0.1429 & 0.1238 \\
\hline
\end{tabular}

TABLE 7. The amount of location impact factor.

\begin{tabular}{llll}
\hline \hline Hospital & 0.6298 & Governmental Office & 0.3097 \\
Clinic & 0.5665 & Shopping Center & 0.2993 \\
Health Center & 0.4735 & Supermarket & 0.2742 \\
Seminaries & 0.4953 & Movie Theater & 0.1361 \\
University and Institute & 0.3884 & Museum & 0.0879 \\
High School & 0.2946 & Library & 0.1957 \\
Mosque and Hussainiya & 0.5002 & Pilgrim Residential & 0.3604 \\
Bus Terminal & 0.5347 & Hotel & 0.1761 \\
Subway Station & 0.4588 & Motel & 0.1793 \\
Gas Station & 0.4309 & Inn & 0.2276 \\
CNG Station & 0.4157 & & \\
\hline
\end{tabular}

the negative criteria (recreational nature), using the questionnaire, TOPSIS method was employed to calculate every location's impact factor; the obtained results are provided in Table 7.

\section{Step 5. Determining the restrictive parameters for the districts and locations}

Because of the high costs of manufacture of e-charity boxes and the lack of people's familiarity with them, it is not possible to replace the conventional charity boxes with electronic ones all at once. Therefore, in the first place, some restrictions were implemented on the maximum number of e-charity boxes, which was 80 . Besides the aim to acculturate and familiarize people with e-charity boxes, there were some restrictions applied in the mathematical model as well, namely to assign at least one e-charity box to each district and each location, and, on the other hand, to avoid the accumulation of e-charity boxes in one district or location type. The maximum number of e-charity boxes that could be installed in each district was estimated based on the experts' opinions and according to the number of potential locations in each district; the results are displayed in Table 8 . The maximum number of e-charity boxes that could be installed in each location type was estimated based on the experts' opinions and according to the number of potential locations in each location; the results of are illustrated in Table 9.

\section{Step 6. Solving the mathematical model}

The mathematical model of the problem was coded by MATLAB version 9.2 on a computer with Windows 10 operating system. The model contains 2 objectives, 129 constraints, and 1024 variables. In order to solve this model that contains binary variables, Branch and Bound algorithm was applied, which is one of the most common algorithms for solving the integer programming problems, particularly binary ones.

Given the real data, obtaining the final model of the problem, as a single-objective model, firstly requires the extraction of the optimal amount of each objective according to the restrictions. Accordingly, a single-objective modeling was performed for each of the above objectives. The optimal amount of each objective was 188425892 
TABLE 8. Maximum number of e-charity boxes that could be installed in each district.

\begin{tabular}{llllllllll}
\hline \hline District & $\mathrm{MFD}_{i}$ & District & $\mathrm{MFD}_{i}$ & District & $\mathrm{MFD}_{i}$ & District & $\mathrm{MFD}_{i}$ & District & $\mathrm{MFD}_{i}$ \\
\hline 1 & 4 & 10 & 9 & 19 & 7 & 28 & 24 & 37 & 7 \\
2 & 6 & 11 & 5 & 20 & 5 & 29 & 11 & 38 & 5 \\
3 & 11 & 12 & 10 & 21 & 10 & 30 & 14 & 39 & 8 \\
4 & 10 & 13 & 6 & 22 & 10 & 31 & 9 & 40 & 11 \\
5 & 1 & 14 & 10 & 23 & 8 & 32 & 14 & 41 & 12 \\
6 & 6 & 15 & 7 & 24 & 12 & 33 & 11 & 42 & 3 \\
7 & 7 & 16 & 11 & 25 & 17 & 34 & 6 & 43 & 15 \\
8 & 4 & 17 & 8 & 26 & 17 & 35 & 5 & & \\
9 & 10 & 18 & 20 & 27 & 26 & 36 & 8 & & \\
\hline
\end{tabular}

TABLE 9. Maximum number of e-charity boxes that could be installed in each location.

\begin{tabular}{llll}
\hline \hline Location & $\mathrm{MFL}_{j}$ & Location & $\mathrm{MFL}_{j}$ \\
\hline Hospital & 18 & Governmental Office & 50 \\
Clinic & 27 & Shopping Center & 20 \\
Health Center & 12 & Supermarket & 8 \\
Seminaries & 15 & Movie Theater & 3 \\
University and Institute & 5 & Museum & 50 \\
High School & 6 & Library & 22 \\
Mosque and Hussainiya & 1 & Pilgrim Residential & 50 \\
Bus Terminal & 20 & Hotel & 5 \\
Subway Station & 20 & Motel & 35 \\
Gas Station & 8 & Inn & 20 \\
CNG Station & 5 & & \\
\hline
\end{tabular}

and 92.68, respectively. As it can be observed in Table 10, the optimal locations of e-charity boxes or the results of ultimate objective function of LP-Metric method were obtained via equation (4.9). The extracted locations in both objectives were compared and analyzed independently via single-objective function of LP-Metric method and the results are delineated in Table 11. As it is clear in Table 11, 16 out of 80 locations of LP-Metric method function were in common with the other two objectives, which suggests the significance of these locations; in other words, the gained benefit, district, and location of these points were all optimal. Furthermore, 49 locations of LP-Metric method function were in common with the first objective, and six locations were in common with the second objective. There were nine locations in LP-Metric method function which were not independently optimal in any of the two objectives. These numbers indicate two advantages: the first one is prioritizing installment of the 80 e-charity boxes, while the second is pointing out the fact that considering the data about the amount of money donation to determine the optimal locations, which was a common practice in the past, was inappropriate and, consequently, the impact of district and location on donation motivation should also be taken into account. Accordingly, 20\% of determining the optimal locations (22 locations out of 80 optimal locations) could be explained by the second objective, i.e. maximizing the motivation for donation in district and location type. It can also be implied from Table 11 that despite being optimal, 15 locations in the first objective and 58 ones in the second objective were found optimal in LP-Metric method function. Table 12 displays the number of e-charity boxes allocated to each location type based on each objective and LP-Metric method function. As it can be seen in this table, subway stations, hospitals, and Mosques and Hussainiyas allocated the most optimal location choices; to explain the reasons, it can be mentioned that: hospitals are in an advantageous condition when it comes to the both objectives, i.e. the amount of benefit and donation motivation; the subway stations 
TABLE 10. Optimal locations of e-charity boxes.

\begin{tabular}{lllllllllllllllll}
\hline \hline $\begin{array}{l}\text { Optimal } \\
\text { location }\end{array}$ & $i$ & $j$ & $k$ & $\begin{array}{l}\text { Optimal } \\
\text { location }\end{array}$ & $i$ & $j$ & $k$ & $\begin{array}{l}\text { Optimal } \\
\text { location }\end{array}$ & $i$ & $j$ & $k$ & $\begin{array}{l}\text { Optimal } \\
\text { location }\end{array}$ & $i$ & $j$ & $k$ \\
\hline 1 & 1 & 9 & 1 & 21 & 17 & 12 & 1 & 41 & 26 & 7 & 9 & 61 & 32 & 9 & 1 \\
2 & 2 & 5 & 1 & 22 & 18 & 18 & 1 & 42 & 26 & 9 & 2 & 62 & 33 & 16 & 1 \\
3 & 3 & 2 & 2 & 23 & 18 & 5 & 31 & 43 & 27 & 19 & 6 & 63 & 34 & 3 & 1 \\
4 & 4 & 6 & 7 & 24 & 18 & 9 & 1 & 44 & 27 & 19 & 7 & 64 & 35 & 7 & 2 \\
5 & 5 & 5 & 1 & 25 & 19 & 7 & 4 & 45 & 27 & 20 & 3 & 65 & 36 & 2 & 1 \\
6 & 6 & 7 & 5 & 26 & 20 & 10 & 2 & 46 & 27 & 4 & 2 & 66 & 37 & 9 & 1 \\
7 & 7 & 2 & 1 & 27 & 21 & 1 & 1 & 47 & 27 & 7 & 14 & 67 & 38 & 7 & 3 \\
8 & 8 & 7 & 1 & 28 & 21 & 11 & 2 & 48 & 28 & 21 & 1 & 68 & 39 & 1 & 1 \\
9 & 9 & 8 & 1 & 29 & 21 & 7 & 2 & 49 & 28 & 4 & 2 & 69 & 39 & 2 & 1 \\
10 & 9 & 9 & 2 & 30 & 22 & 1 & 1 & 50 & 28 & 7 & 7 & 70 & 39 & 9 & 3 \\
11 & 10 & 9 & 3 & 31 & 23 & 1 & 1 & 51 & 28 & 7 & 7 & 71 & 40 & 1 & 1 \\
12 & 11 & 8 & 1 & 32 & 23 & 14 & 1 & 52 & 29 & 1 & 1 & 72 & 40 & 13 & 1 \\
13 & 12 & 9 & 3 & 33 & 23 & 8 & 1 & 53 & 29 & 13 & 1 & 73 & 41 & 9 & 1 \\
14 & 13 & 9 & 6 & 34 & 24 & 1 & 1 & 54 & 29 & 9 & 1 & 74 & 18 & 18 & 50 \\
15 & 14 & 1 & 1 & 35 & 24 & 1 & 2 & 55 & 30 & 2 & 1 & 75 & 43 & 1 & 1 \\
16 & 14 & 2 & 1 & 36 & 24 & 3 & 1 & 56 & 30 & 2 & 2 & 76 & 18 & 18 & 50 \\
17 & 14 & 5 & 2 & 37 & 25 & 1 & 1 & 57 & 30 & 9 & 2 & 77 & 43 & 15 & 1 \\
18 & 14 & 9 & 3 & 38 & 25 & 1 & 2 & 58 & 31 & 10 & 1 & 78 & 43 & 7 & 7 \\
19 & 15 & 2 & 1 & 39 & 25 & 7 & 1 & 59 & 32 & 17 & 1 & 79 & 43 & 9 & 2 \\
20 & 16 & 1 & 1 & 40 & 26 & 10 & 3 & 60 & 32 & 2 & 2 & 80 & 43 & 9 & 3 \\
\hline
\end{tabular}

TABLE 11. Comparative analysis of optimal locations in two objectives and LP-Metric function.

\begin{tabular}{llll}
\hline \hline First objective & Second objective & LP-Metric function & Number of locations \\
\hline$*$ & $*$ & $*$ & 49 \\
$*$ & $*$ & $*$ & 20 \\
& $*$ & $*$ & 6 \\
$*$ & & & 9 \\
& $*$ & & 15 \\
\hline
\end{tabular}

are in an advantageous condition in terms of the amount of benefit; and Mosques and Hussainiyas are in an advantageous condition in terms of the second objective. i.e. donation motivation. Table 13 demonstrates the distribution of optimal locations in 43 districts of the district under study. Due to the not-exceeding-80-boxes restriction, the majority of the districts were only assigned 1 e-charity box, yet districts $43,28,27$, and 14 were allocated more than 1 box as a result of their appropriate condition in terms of the both objectives.

\section{Conclusion}

It is one of the duties of members of a society to support underprivileged people and families around them. Applying the scientific methods in locating the facilities (charity boxes) can assist to a large extent to the optimization of the obtained benefits, cleanliness of the environment, and people's health. Due to this fact, post to collecting the data and estimating the required parameters, the present study aimed to introduce the effective criteria on donation in every district and location type. Effective criteria on donation in terms of districts were determined via a parameter called "district impact factor", which was obtained from the seven 
TABLE 12. Number of e-charity box allocated to each location type.

\begin{tabular}{llll}
\hline \hline Location & First objective & Second objective & LP-Metric function \\
\hline Hospital & 12 & 17 & 14 \\
Clinic & 6 & 14 & 9 \\
Health Center & 2 & 1 & 2 \\
Seminaries & 1 & 3 & 2 \\
University and Institute & 6 & 1 & 4 \\
High School & 1 & 1 & 1 \\
Mosque and Hussainiya & 6 & 29 & 12 \\
Bus Terminal & 3 & 1 & 3 \\
Subway Station & 18 & 1 & 15 \\
Gas Station & 3 & 1 & 2 \\
CNG Station & 1 & 1 & 1 \\
Governmental Office & 10 & 1 & 4 \\
Shopping Center & 1 & 1 & 1 \\
Supermarket & 1 & 1 & 1 \\
Movie Theater & 1 & 1 & 1 \\
Museum & 1 & 1 & 1 \\
Library & 1 & 1 & 1 \\
Pilgrim Residential & 1 & 1 & 1 \\
Hotel & 3 & 18 & 2 \\
Motel & 1 & 1 & 1 \\
Inn & 1 & 1 & 1 \\
Sum & 80 & 80 & 80 \\
\hline
\end{tabular}

TABLE 13. Allocation of optimal locations in districts.

\begin{tabular}{|c|c|c|c|c|c|c|c|c|c|c|c|c|c|c|c|}
\hline Districts & $\begin{array}{l}\text { First } \\
\text { objective }\end{array}$ & $\begin{array}{l}\text { Second } \\
\text { objective }\end{array}$ & $\begin{array}{l}\text { LP- } \\
\text { Metric } \\
\text { function }\end{array}$ & $\mathrm{D}$ & $\mathrm{FO}$ & $\mathrm{SO}$ & $\mathrm{LP}$ & $\mathrm{D}$ & $\mathrm{FO}$ & $\mathrm{SO}$ & LP & $\mathrm{D}$ & $\mathrm{FO}$ & $\mathrm{SO}$ & LP \\
\hline 1 & 1 & 1 & 1 & 12 & 1 & 1 & 1 & 23 & 3 & 1 & 3 & 34 & 1 & 1 & 1 \\
\hline 2 & 1 & 1 & 1 & 13 & 1 & 1 & 1 & 24 & 3 & 2 & 3 & 35 & 1 & 1 & 1 \\
\hline 3 & 1 & 1 & 1 & 14 & 3 & 1 & 4 & 25 & 3 & 2 & 3 & 36 & 1 & 1 & 1 \\
\hline 4 & 1 & 1 & 1 & 15 & 1 & 1 & 1 & 26 & 3 & 1 & 3 & 37 & 1 & 1 & 1 \\
\hline 5 & 1 & 1 & 1 & 16 & 1 & 1 & 1 & 27 & 3 & 23 & 5 & 38 & 1 & 1 & 1 \\
\hline 6 & 1 & 1 & 1 & 17 & 1 & 1 & 1 & 28 & 3 & 11 & 4 & 39 & 3 & 1 & 3 \\
\hline 7 & 1 & 1 & 1 & 18 & 3 & 1 & 3 & 29 & 3 & 1 & 3 & 40 & 2 & 1 & 2 \\
\hline 8 & 1 & 1 & 1 & 19 & 1 & 1 & 1 & 30 & 5 & 1 & 3 & 41 & 1 & 1 & 1 \\
\hline 9 & 3 & 1 & 2 & 20 & 1 & 1 & 1 & 31 & 2 & 1 & 1 & 42 & 1 & 1 & 1 \\
\hline 10 & 3 & 1 & 1 & 21 & 3 & 2 & 3 & 32 & 1 & 1 & 1 & 43 & 4 & 3 & 6 \\
\hline 11 & 1 & 1 & 1 & 22 & 1 & 1 & 1 & 33 & 1 & 1 & 1 & & & & \\
\hline
\end{tabular}

proposed criteria, i.e. the mean of donation from pathways in a district, the mean of household donation, the proportion of donation in the population, the proportion of total household in population, the proportion of over-twenty-year-olds in the population, the proportion of the employed in the population, the percentage of house owners, and the percentage of houses bigger than 100 square meters. The effective criteria on donation in terms of location were also determined via a parameter called "location impact factor", which was obtained from the six proposed criteria, i.e. religious nature, recreational nature, the probability of danger or threat in the location, human traffic rate, donation availability for the donors, and the probability of women presence. 
In order to determine the potential locations, 1024 locations across 43 districts and 21 location types across Mashhad were employed. Then, considering the two objectives of the study, i.e. maximizing the total donation benefit and maximizing the total donation motivation, the mathematical algorithm was implemented using MATLAB software. In order to consolidate the two objectives into one, the LP-Metric method function was applied and finally 80 eventual locations were defined as the optimal locations. In order to better utilize e-charity boxes, the study firstly suggests that after locating their optimal locations, attention should be paid to their design and position; secondly, it can be suggested that, from time to time, the mathematical algorithm should be implemented with new data to discover new or alternative locations. For further research, it is suggested that, in the first step, locating should be implemented by the assumption of assigning e-charity boxes in pathways, and in the second step, modeling the place of both locations and pathways ought to be be implemented. Finally, we suggest that the algorithm is modelled by means of the other two approaches, i.e. the Fuzzy logic and the stochastic process.

Acknowledgements. The authors thank the Research Council of the Ferdowsi University of Mashhad for supporting this work.

\section{REFERENCES}

[1] H.R.L. Azad and N.S. Boushehri, Billboard advertising modeling by using network count location problem. Int. J. Traffic Transp. Eng. 4 (2014) 146-160.

[2] S. Banerjee, M.M. Kabir, N.K. Khadem and C. Chavis, Optimal locations for bikeshare stations: a new GIS based spatial approach. Transp. Res. Interdiscip. Perspect. 4 (2020) 100101.

[3] R. Bekkers and I. Veldhuizen, Geographical differences in blood donation and philanthropy in the Netherlands - what role for social capital? Tijdschr. Econ. Soc. Geogr. 99 (2008) 483-496.

[4] O. Berman, D. Krass and J. Wang, The probabilistic gradual covering location problem on a network with discrete random demand weights. Comput. Oper. Res. 38 (2011) 1493-1500.

[5] Bielefeld, W., Murdoch, J.C. and Waddell, P., The influence of demographics and distance on nonprofit location. NVSQ 26 (1997), 207-225.

[6] R. Blanquero, E. Carrizosa and G. Boglárka, Maximal covering location problems on networks with regional demand. Omega 64 (2016) 77-85.

[7] G. Bramley, N. Dempsey, S. Power, G. Bramley and C. Brown, What is 'social sustainability', and how do our existing urban forms perform in nurturing it sustainable communities and green futures, Conference, Bartlett School of Planning, University College London (2006).

[8] R. Church and C. ReVelle, The maximal covering location problem. Reg. Sci. Assoc. 38 (1974) 101-118.

[9] A.A. Coco, A.C. Santos and T.F. Noronha, Formulation and algorithms for the robust maximal covering location problem. Electron. Notes in Disc. Math. 64 (2018) 145-154.

[10] S. Davari, M.H.F. Zarandi and I.B. Turksen, A greedy variable neighborhood search heuristic for the maximal covering location problem with fuzzy coverage radii. Knowl. Based Syst. 41 (2013) 68-76.

[11] R.Z. Farahani and M. Hekmatfar, Facility Location: Concepts, Models, Algorithms and Case Studies. Springer Science \& Business Media (2009).

[12] G. Geng and R. Wardlaw, Application of multi-criterion decision making analysis to integrated water resources management. Water Resour. Manage. 27 (2013) 3191-3207.

[13] R. Gupta, S.K. Muttoo and S.K. Pal, Fuzzy c-means clustering and particle swarm optimization based scheme for common service center location allocation. Appl. Intell. 47 (2017) 624-643.

[14] C.L. Hwang and A.S.M. Masud, Multiple Objective Decision Making - Methods and ipplications: A State-of-the-Art Survey. Springer Science \& Business Media 164 (2012).

[15] C.L. Hwang and K. Yoon, Methods for Multiple Attribute Decision Making (1981) 58-191.

[16] A. Jahan and K.L. Edwards, A state-of-the-art survey on the influence of normalization techniques in ranking: improving the materials selection process in engineering design. Mater. Des. 1980-2015 65 (2015) 335-342.

[17] Ö. Kabak and B. Ervural, Multiple attribute group decision making: a generic conceptual framework and a classification scheme. Knowl. Based Syst. 123 (2017) 13-30.

[18] G. Kannan, A hybrid approach using ISM and fuzzy TOPSIS for the selection of reverse logistics provider. Resour. Conserv. Recycl. 1 (2009) 28-36.

[19] C. Lee and J. Han, Benders-and-price approach for electric vehicle charging station location problem under probabilistic travel range. Transp. Res. Part B: Methodol. 106 (2017) 130-152.

[20] T.S. Liou and M.J.J. Wang, Fuzzy weighted average: an improved algorithm. Fuzzy Sets Syst. 3 (1992) $307-315$.

[21] R. Lotfi, Y.Z. Mehrjerdi and N. Mardani, A multi-objective and multi-product advertising billboard location model with attraction factor mathematical modeling and solutions. Int. J. Appl. Logist. (IJAL) 7 (2017) 64-86. 
[22] M. Lwin and I. Phau, Characteristics of charitable donors in Australia recent advances in retailing and services science, Conference Proceedings: Recent Advances In Retailing And Services science (2010).

[23] J.D. Marx, V.B. Carter, N.K. Khadem and C. Chavis, Factors influencing US charitable giving during the great recession: implications for nonprofit administration. Adm. Sci. 4 (2014) 350-372.

[24] M.F. Moeen and K.H. Taghizadeh, A new heuristic solution method for maximal covering location-allocation problem with M/M/1 queueing system. J. Sci. Islamic Repub. Iran 23 (2012) 67-75.

[25] R. Narasimhan, S.K. Talluri, J. Sarkis and A. Ross, Efficient service location design in government services: a decision support system framework. J. Oper. Manage. 23 (2005) 163-178.

[26] C. Park and S.Y. Sohn, An optimization approach for the placement of bicycle-sharing stations to reduce short car trips: an application to the city of Seoul. Transp. Res. Part A: Policy Pract. 105 (2017) 154-166.

[27] S.H.R. Pasandideh, S.T.A. Niaki and K. Asadi, Optimizing a bi-objective multiproduct multi-period three echelon supply chain network with warehouse reliability. Expert Syst. App. 42 (2015) 2615-2623.

[28] N.R. Patel, Locating rural social service centers in India. Manage. Sci. 25 (1979) 22-30.

[29] M.A. Pereira, L.C. Coelho, L.A. Lorena and L.C. De Souza, Hybrid method for the probabilistic maximal covering locationallocation problem. Comput. Oper. Res. 57 (2015) 51-59.

[30] M. Pouraliakbari, M. Mohammadi and A. Mirzazadeh, Analysis of maximal covering location-allocation model for congested healthcare systems in user choice environment. Int. J. Ind. Syst. Eng. 28 (2018) 240-274.

[31] S.U. Rahman and D.K. Smith, Use of location-allocation models in health service development planning in developing nations. Eur. J. Oper. Res. 123 (2000) 437-452.

[32] A.P. Sargaonkar, B. Rathi and A. Baile, Identifying potential sites for artificial groundwater recharge in sub-watershed of River Kanhan, India. Environ. Earth Sci. 6 (2010) 1-10.

[33] J.A. Tali, M.M. Malik, S. Divya, A. Nusrath and B. Mahalingam, Location-allocation model applied to urban public services: spatial analysis of fire stations in Mysore urban area Karnataka, India. Int. J. Adv. Res. Dev. 2 (2017) 795-801.

[34] I. Vinogradova, Multi-attribute decision-making methods as a part of mathematical optimization. Mathematics 7 (2019) 915.

[35] K. Yao and I. Phau, Who gives the determinants of charitable giving, volunteering, and their relationship (2015).

[36] E.K. Zavadskas and Z. Turskis, Multiple criteria decision making (MCDM) methods in economics: an overview. Technol. Econ. Dev. Econ. 17 (2011) 397-427. 